\title{
ANXIETY INCREASES THE WILLINGNESS TO BE EXPOSED TO COVID-19 RISK AMONG YOUNG ADULTS IN FRANCE
}

\author{
Fabrice Etilé ${ }^{1,2 *}$, Pierre-Yves Geoffard ${ }^{1}$
}

\author{
Affiliations \\ ${ }^{1}$ Paris School of Economics, 48 Boulevard Jourdan, 75014 France. \\ ${ }^{2}$ INRAE, UMR 1393 PjSE, 48 Boulevard Jourdan, 75014 France
}

\begin{abstract}
The COVID-19 outbreak has generated significant uncertainty about the future, especially for young adults. Health and economic threats, as well as more diffuse concerns about the consequences of COVID-19, can trigger feelings of anxiety, leading individuals to adopt uncertainty-reducing behaviours. We tested whether anxiety was associated with an increase in willingness to be exposed to the risk of COVID-19 infection (WiRE) using an online survey administered to 3,110 French individuals aged between 18 and 35 years old during the lockdown period (April 2020). Overall, 56.5\% of the sample declared a positive WiRE. Unemployment was associated with a higher WiRE (+8.2 percentage points (pp); 95\% CI +0.9$15.4 \mathrm{pp})$. One standard deviation increases in income $(+1160 €)$ and psychological state anxiety raised the WiRE by $+2.7 \mathrm{pp}(95 \% \mathrm{CI}:+1.1-4.4 \mathrm{pp})$ and $+3.9 \mathrm{pp}(95 \% \mathrm{CI}:+1.6-6.2 \mathrm{pp})$, respectively. A one standard deviation increase in perceived hospitalisation risk was associated with a $-4.1 \mathrm{pp}(95 \% \mathrm{CI}:-6.2-2.1 \mathrm{pp})$ decrease in the WiRE. Overall, our results suggest that both the prospect of economic losses and psychological anxiety can undermine young adults' adherence to physical distancing recommendations. Public policies targeting young adults must consider both their economic situation and their mental health, and they must use uncertaintyreducing communication strategies.
\end{abstract}

\section{Correspondence should be addressed to}

*Fabrice Etilé, email: fabrice.etile@psemail.eu

Short title: Willingness to COVID-19 risk exposure 


\section{Introduction}

Many governments have "flattened the curve" of the first wave of the COVID-19 (SARS-CoV2) pandemic by implementing stringent restrictions on individuals' freedom of movement and socialisation. Once the first wave subsided, they switched to lighter containment strategies based on physical distancing, population testing, contact tracing, and isolation and treatment. While this approach has helped balance social and economic needs within the capacity of the health system ${ }^{1-4}$, its effectiveness crucially depends on the willingness of individuals to comply with physical distancing requirements and testing recommendations ${ }^{5-8}$.

In France, COVID-19 infections started to increase in young adults again at the end of summer 2020, triggering a second epidemic wave that spread rapidly to older age groups (see the Supplementary Appendix, Figure SA1). Possible explanations for the reduced prevention efforts among young adults include belief in their low level of health risk, "distancing fatigue", and the need for social interactions after two months of lockdown and many additional weeks with severe restrictions on social venues. Here, we document an additional explanation: deliberate risk exposure.

Understanding whether and why young adults may be inclined to engage in deliberate risk exposure is important for designing effective public health strategies. During the lockdown period, some U.S. media reported rumours of "COVID parties", whereby young individuals would deliberately meet with acquaintances known to be infected and contagious. Even though there is no firm evidence of such practices, these rumours emphasise that intentional selfinfection may appear to young healthy adults as a reasonable individual strategy of adaptation to their current environment.

We hypothesised that the COVID-19 outbreak has generated radical uncertainty that can trigger feelings of anxiety, leading young adults to deliberately expose themselves to risk. COVID-19 has thwarted the aspirations and the existence of many young adults who face gloomy economic prospects and physical distancing measures that they may perceive as a threat to their social bonds and identity 9 . Uncertainty about future was and still is compounded by the ambiguities in public health communication about the risks of the disease, the policy responses being taken, and the indeterminacy of the complex array of economic, political, and social disruptions resulting from the outbreak. Empirical and theoretical works in psychology have largely documented the impact of the subjective experience of uncertainty on the generation of negative emotions, especially anxiety ${ }^{10}$. Heightened anxiety levels pose an adaptative challenge to individuals and thus increase the psychological benefits of uncertainty-reducing actions ${ }^{11}$. What is possibly at stake, at least among some young adults, is a willingness to eliminate the infection risk and the emotional distress produced by the pandemic as soon as possible. If contracting COVID-19 is perceived as slightly risky in the short term but reduces uncertainty regarding the future, then it may appear preferable to increase one's risk exposure in order to resolve that uncertainty sooner rather than later ${ }^{12}$. This behavioural mechanism driving deliberate risk exposure also finds theoretical and empirical support in economic research on decision-making processes. Economic theory has provided formal foundations for appraising individual preferences for the earlier resolution of uncertainty ${ }^{13}$ - and their links with ambiguity 
aversion $^{14}$. Experimental tests of these models have shown that individuals prefer an earlier resolution of uncertainty when it is associated with an increase in expected future consumption utility $^{15,16}$.

To analyse the relationship between anxiety and individual willingness to risk exposure (WiRE) to COVID-19, we conducted an online survey in a sample of young French adults aged between 18 and 35 during the period of strict lockdown in the entire country (April 2020). We deliberately framed our WiRE questions to make the possible individual benefits of risk exposure in terms of immunity to COVID-19 and a reduction in future uncertainty more salient, since these would be the only logical rationale for intentionally exposing oneself to infection. Anxiety can have as many sources as there are dimensions of uncertainty, and individuals are likely to differ in their behavioural and affective responses to each of these dimensions ${ }^{17}$.

Anxiety can vary across individuals according to their economic situation and how they perceive the risk of COVID-19 to be conditional on the information they have. We therefore analysed the association between income, labour force status and perceived health risks and WiRE. From a rational choice perspective, it is worth increasing self-protection efforts up to the point where the marginal reduction in health risks does not offset the marginal increase in costs related to foregone benefits from an unconstrained social life and economic activity. Similarly, deliberate risk exposure will depend on the trade-off between the prospect of financial losses in the absence of a return to normal economic life and the expected consequences of infection ${ }^{18}$. While we expect deliberate risk exposure to decrease with the perceived risk of health dangers, income and labour force status may be ambiguously related to the benefits of risk exposure. On the one hand, high-income individuals and those with good job market positions have more to lose from enduring potentially severe health symptoms. On the other hand, they are better self-insured against health shocks than low-income individuals and might also have preferred contracting COVID-19 during the lockdown, as economic activity had slowed down and income losses were insured by the French state at that point, rather than during the post-lockdown period of economic recovery.

However, in addition to economic incentives and health risk beliefs, emotions can directly affect an individual's willingness to expose him or herself to risk and can indirectly affect this by shaping his or her risk perceptions and orienting his or her decision-making processes ${ }^{19,20}$. We thus examined whether psychological state anxiety had an independent direct effect on WiRE.

Finally, in addition to these two categories of anxiety-related motivations - incentives and emotions - compliance with physical distancing norms depends on how much individuals care about the social consequences of their actions ${ }^{21}$. Recent empirical studies reveal that higher levels of social values such as generalised trust, altruism and reciprocity are associated with higher compliance with confinement measure ${ }^{22-28}$. We specifically focused on generalised trust and reciprocity, as a large body of literature in the social sciences has previously analysed the role of these social values in the emergence of cooperative behaviours at a collective level ${ }^{29-32}$, and the social epidemiology literature has also documented their associations with various health outcomes at the individual and community levels ${ }^{33-35}$. We expected that a higher 
tendency to endorse these social values would be associated with lower WiRE and less sensitivity to anxiety-related factors.

While generalised trust and reciprocity refer to the expectation that others will in general act in a way that contributes to the common good or will, at least, refrain from harmful actions, individuals may behave differently in personal interactions with particular groups of individuals, depending on whether they feel more or less close to them. We thus also measured psychological closeness with family members, friends, neighbours, and colleagues. In terms of social values, we thus specifically tested whether WiRE was lower in individuals who felt relatively closer to their family than to friends, neighbours, or colleagues and whether this 'family orientation' was also a moderating variable in the relationship between anxiety and WiRE.

\section{Methods}

\section{Setting of the study and statement}

We conducted a cross-sectional analysis using data from an online survey that was composed of an experimental investigation on subjective identity, and a general questionnaire including a COVID-19 module. FE had started to design the survey prior to the outbreak as part of a research programme on the relationships between subjective identity and economic preferences in young adults. This research program and the experimental section of the survey are not related to the COVID-19 crisis (see the pre-registration of the experimental hypotheses at https://osf.io/mhty3). After the lockdown and confinement policy measures enacted by the French government on March $16^{\text {th }}$, we (FE and PYG) decided to add the specific COVID-19 module that was inserted in the questionnaire at a distance from the experimental treatments and measures. Given the time constraints and the crisis context, the hypotheses developed and tested in the present study were not subjected to a specific pre-registration.

The questionnaire was developed using Qualtrics online survey services. The survey respondents were recruited by Qualtrics and paid $4.45 €$ per completed questionnaire. Qualtrics distributed the survey between April $10^{\text {th }}$ and April $20^{\text {th }}$. The dataset was made available to us on April $21^{\text {st. }}$.

All methods were performed in accordance with relevant French and European guidelines and regulations. The whole survey was approved by the Paris School of Economics IRB (Certificate 2020-009). Although PYG is a member of the Paris School of Economics IRB, PYG did not participate in reviewing the proposal. The IRB waived the need for informed consent as (i) respondents' anonymity and RGPD compliance were guaranteed by Qualtrics; (ii) the experimental section of the survey used innocuous priming (iii) respondents were free to opt out of the survey at any moment.

More details on the overall survey structure and content are presented in Section A of the Supplementary Appendix (SA). The data and codes used for producing the results are available at https://osf.io/gesyt/. 


\section{Target population and sample selection}

The target sample was specified to include only individuals aged between 18 and 35 . The sampling procedure was designed to have equal quotas of women and men and of individuals aged from 18 to 25 (inclusive) and 26 or over. The total analytical sample included 3,100 participants, consisting of 1,570 women and 1,530 men. Details about sample selection can be found in Section B.1 of the SA.

\section{Target outcome}

Our outcome of interest was the self-reported willingness to risk exposure (WiRE) to coronavirus infection. A screening question asked respondents to report whether they thought they had already been infected, with three possible answers: 'No', 'Yes', 'Maybe, I am not sure'. Those who answered negatively or were not certain were then asked to report on a $0-10$ Likert scale their willingness to expose themselves to the risk of infection, where 0 was labelled 'I would not take any risk' and 10 as 'I will take as much risk as I can'. The question was preceded by a short introductory text, based on the state of knowledge about the disease at the time of the survey ${ }^{36}$, emphasising the likely benefit immunity if one recovers from the infection. This was followed by a text warning the respondent that current scientific knowledge indicates that being infected does not guarantee long-term immunity and that the protection of oneself and others requires that contamination risk is minimised by following the government's recommendations and adopting social distancing measures.

\section{Anxiety-related factors}

Health risk beliefs were measured by asking about respondents' subjective expectations about the population-level risks and their own risk of COVID-related hospitalisation. We also included a dummy variable - "COVID negative: unsure" - indicating that the respondent thought that he or she may have already been infected.

Respondents had to report their monthly household income. We adjusted for the number of household units of consumption to produce an equivalised household income variable. We included dummy variables indicating whether the respondent was still working and, if so, whether he or she had arranged to work from home or not. We also collected information on the respondents' employment status before the crisis and constructed dummy variables indicating whether, before the lockdown, the respondent had a permanent job, had a temporary job, was a student, was self-employed, was unemployed, or was out of the labour force.

Psychological anxiety was measured by using the Spielberger state anxiety scale in a 6-item short-form version ${ }^{37}$. Item responses were summed to produce a score from 0 to 18 . Previous studies have shown the impact of gender-specific norms in health-reporting behaviours in France $^{38}$. We therefore standardised the anxiety score using gender-specific means and standard deviations. 
Generalised trust was measured through a single question that was drawn from the European Social Survey ${ }^{39}$ and had previously been used in studies on health and trust ${ }^{33}$. Respondents had to rate on a 0 to 10 Likert scale whether "most people can be trusted or one needs to be very careful when dealing with people". Reciprocity was measured by presenting respondents with a choice scenario in which they had to choose from among a group of gifts of different value what they would give to a stranger who had previously helped them ${ }^{40}$.

Psychological closeness with others was measured by using inclusion of other in the self (IOS) scales where individuals report on a 1 to 7 Likert scale how close they feel to another given individual or group of individuals ${ }^{41}$. Respondents had to provide ratings for seven categories of individuals: their partner, their parents, their family, their long-term friends, their work or university friends, people and friends from their neighbourhood, and people they socialise with through organizations. We used the seven ratings to construct two average scores, the first for the respondent's partner, parents and other family members and the second for the respondent's other relationships. We hypothesised that risk-taking behaviour would be affected differently if the individual is more family oriented than if he or she is more community (friends, neighbours, colleagues) oriented. Therefore, we defined the relative closeness of individuals with their relatives to their closeness with their other acquaintances by dividing the former score by the latter. This ratio measures the relative 'family orientation' of individuals. We also computed the average of all ratings to control for inter-individual variability in response styles (see Appendix A.8). The trust, reciprocity and family-orientation variables were all standardised (z-score) by their gender-specific means and standard deviations.

\section{Statistical analysis}

For our main analysis, we fitted ordered logit models (using Stata 16.1) with WiRE as the dependent variable. Our baseline specification included age as a continuous variable and dummy variables for gender, education (in three groups: did not complete high school, completed high school, higher education), partnership status, parental status, income, and labour force status. We adjusted for the confounding effect of risk and time preferences. We also controlled for heterogeneity in lockdown conditions: we introduced one dummy variable that indicated whether the respondent was locked down and temporarily not working, and a dummy variable that indicated whether he or she was in lockdown with someone close. These two variables were selected after a specification search that revealed no effect of other characteristics of lockdown conditions (see SA B.2). We also controlled for survey-specific effects via a set of dummy variables identifying the various experimental groups, with deviation contrast coding to ease the interpretation of the effects on the other dummy variables. These fixed effects were never significant in our regressions. We also included dummies for each quintile of the total survey duration as a means of improving the precision of the estimates and controlling for heterogeneity in response quality.

Starting from a baseline model that included the variables for incentives and the control variables, we successively added health risk beliefs and anxiety. We then tested whether social values and family orientation modulate the effects of incentives and anxiety by introducing appropriate interaction terms. 
As the distribution of answers displayed a large grouping on 0 , we decided to focus our presentation of the results on the intention to take on at least some risk of exposure, i.e., reporting a positive WiRE. We used the post-estimation Stata command - margins - to report the marginal effect of variables on the probability that an individual's WiRE would be greater than 0 . The results should be interpreted in terms of the change in percentage points for marginal changes of the covariates.

\section{Results}

\section{Descriptive statistics}

The first column of Table 1 displays the average sociodemographic characteristics of the survey respondents. The sample had an almost equal proportion of women to men and individuals aged 25 or under to individuals over 25 , as determined by the sampling design. Nearly $95 \%$ of the respondents were born in France, 53.7\% had attended higher education, and half of them were living with a partner. While $20.7 \%$ had at least one child, only $2.6 \%$ were single parents. The average monthly equivalised income was $1,660 €$, while the median income was lower $(1,400 €)$. The income distribution was right-skewed (the skewness equalled 1.66). While more than $25 \%$ of respondents had a monthly income lower than $1,000 €$, another quarter had a monthly income higher than $2000 €$. Approximately $30 \%$ of respondents were still students, $42.7 \%$ had a permanent job, $12 \%$ had a temporary job, $5.3 \%$ were self-employed and $5.6 \%$ were unemployed. We discuss the representativeness of this sample later in the article.

Nearly $7 \%$ of the respondents (280) reported that they believed they had already been infected by COVID-19. Of these 'COVID-positive' respondents, only $7.5 \%$ provided this answer because they had been tested, 30.5\% reported this because a doctor told them they had had it, and $62 \%$ based their answer only on symptoms they had had. Of the 2,880 'COVIDnegative' respondents, $71.4 \%$ were sure that they had not caught it, and the remaining $28.6 \%$ were unsure. The second column of Table 1 provides the descriptive statistics for the subsample of 'COVID-negative' individuals. Their characteristics are almost identical to those of the full sample. Columns 3 and 4 show the descriptive statistics by gender for the 'COVID-negative' respondents. Women were, on average, younger and more educated than men. Women were also more likely to be students than workers, and women in the labour force were more likely to have a temporary job or be unemployed than men in the labour force. This may explain why their equivalised income was lower, with a median of $1,333 €$ compared to $1,528 €$ for men. The samples did not significantly differ in social values or family orientation.

Figure 1 is a histogram of the distribution of the willingness to risk exposure (WiRE), which was self-reported on a 0 (no risk at all) to 10 (maximum risk) Likert scale. This question was asked only to COVID-negative respondents, and the figure plots distinct histograms for confidently negative vs. less confidently negative respondents. A majority of respondents (56.5\% on average) were willing to take at least some risk, with a higher percentage $(63.4 \%)$ reported by those who were unsure about their negative COVID status. 
Figure 2 shows the distributions of subjective beliefs regarding COVID hospitalisation risk for the overall population and for the individuals themselves. Respondents were more optimistic for themselves than for the population. The average subjective probability of hospitalisation was $17.8 \%$ for the population and $12.9 \%$ for the individuals themselves. Beyond these differences, the probabilities were significantly correlated, with a Pearson correlation of 0.51 .

Figure 3 displays the distributions of scores on the Spielberger status anxiety scale. The scores were standardised using gender-specific means and standard errors. The distributions were slightly right skewed. We plotted the distributions for respondents with positive vs. null values of WiRE (upper panel), for respondents who were sure vs. unsure about being COVID negative (lower left panel), and for those who had a permanent job vs. had a less secure employment status (lower right). Figure 3 shows that higher anxiety levels are found in individuals with a positive WiRE, in those who thought they might have already been infected, and in those with job insecurity. Taken together, these three plots suggest that psychological anxiety may partially mediate the impact of economic conditions and health beliefs on willingness to risk exposure.

\section{Associations with the WiRE}

Figure 4 shows the marginal effects of selected covariates on the WiRE. The target outcome is a binary variable for being willing to take at least some risk vs. no risk at all (WiRE $>0 v s$. $\mathrm{WiRE}=0$ ). The average unconditional probability of being willing to risk exposure was $56.5 \%$. For the interpretation of the marginal effects of discrete covariates, the reference respondent is a man with a permanent job and a higher education degree who was still working during lockdown. Figure 4 is based on the estimation results reported in SA Table C.1., specification 4.

The probability of reporting a positive WiRE was 7.8 percentage points (pp) lower for women than for men after adjusting for a linear age trend, schooling, economic conditions, lockdown status, risk and time preferences, and survey-specific effects. Neither age nor schooling had significant effects, although not having a Baccalaureate's degree (having a UK A Level or less) was marginally significant at the $10 \%$ level in the baseline specification.

Income had a significantly positive effect $(\mathrm{p}<0.01)$. Translated into changes in probability, a one standard deviation $(1,160 €)$ increase in equivalised income implied that the probability of being willing to take some risk was raised by $2.7 \mathrm{pp}$ (95\% CI: +1.1-4.4 pp). Unemployed respondents were also more willing to risk exposure, with a probability 8.2 percentage points higher than that of someone with a permanent job position (95\% CI: $+0.9-15.4 \mathrm{pp})$. Associations with other labour force positions (had a temporary job, were self-employed, were not in the labour force) were close to 0 and never significant. Students were also more willing to take risks, with a $4.2 \mathrm{pp}$ higher probability in the baseline specification, which was significant at the $10 \%$ level only.

The perception of health risks was negatively associated with the WiRE. A one standard deviation $(16.4 \mathrm{pp})$ increase in the subjective probability that people with COVID are hospitalised decreased the probability of being willing to take risks by $-4.1 \mathrm{pp}(95 \% \mathrm{CI}$ : $-6.2-$ 
$2.1 \mathrm{pp})$. We did not detect a specific effect of the difference between beliefs regarding oneself and beliefs regarding the general population. Respondents who were unsure about their COVID status had an $8.5 \mathrm{pp}$ higher probability of being willing to take risks than those who were sure they were COVID negative (95\% CI: $+4.6-12.5 \mathrm{pp})$.

Adding psychological anxiety as a covariate did not significantly alter the estimated effects for economic conditions and health risk beliefs. The marginal effect of income was left unaffected. While the effect of unemployment slightly decreased to $+8.2 \mathrm{pp}$, the association with being a student became slightly smaller $(+3.6 \mathrm{pp})$ and not significant. Although psychological anxiety did not eventually mediate the effect of economic conditions and health risks, it had a large direct impact. A one standard deviation increase in anxiety score was associated with a $+3.9 \mathrm{pp}$ higher probability of being willing to take risk (CI95: +1.6-6.2 pp).

We estimated the full specification on subsamples stratified by gender. The results revealed no significant differences between men and women.

\section{Social values and family orientation: direct effects and effect heterogeneity}

Do social values and family orientation affect the WiRE and the relationship between the WiRE and anxiety-related factors? We started by estimating the direct impact of generalised trust and reciprocity. A one standard deviation increase in the score of generalised trust was associated with a $+4.0 \mathrm{pp}$ increase in the probability of being willing to risk exposure $(+4.8$ for men) - see SA Figure C.2. While high-trust respondents were more willing to risk exposure, we found that reciprocity was negatively and significantly associated with risk exposure for men (-3.7 pp). This association was close to zero and not significant for women. A one standard deviation increase in family orientation had a strong and significant negative impact of $-2.2 \mathrm{pp}$ on the probability of risk exposure. The effect was significant and larger for women (-2.9 pp) than for men ( $-1.7 \mathrm{pp}$, not significant). The effect of the average psychological closeness rating was negative and not significant.

We finally assessed whether the effect of economic conditions, health risk beliefs and anxiety varied across different levels of social values and family orientation with relatives. To this effect, we estimated the full specification with interaction terms between the variables that were significant at the 5\% threshold in the main estimates reported in Figure 4 and trust, reciprocity, and family orientation. We then calculated the marginal effects of income, unemployment, health risk beliefs and anxiety at the first and third quartiles of trust, reciprocity and family orientation. The full results are displayed in Supplementary Appendix Table C.3. Reciprocity had no moderating effects, and the effects of health risk beliefs and anxiety did not vary with trust or family orientation. Table 3 thus reports only the results for the interactions between trust or family orientation and income and unemployment. The income effect was slightly larger for low-trust respondents and those who were relatively less family oriented. Unemployment had a large positive effect for low-trust respondents, with an increase in the WiRE of $+12.4 \mathrm{pp}$. This effect was two and half times lower for high-trust respondents. In contrast, the positive effect of unemployment was higher for more family-oriented respondents 
(+9.0 pp for highly family-oriented respondents vs. $+6.2 \mathrm{pp}$ for low family-oriented respondents).

\section{Discussion}

This research shows that an important proportion of young adults are willing to deliberately expose themselves to the risk of infection and that this attitude is fuelled by anxiety.

Our WiRE measure was intentionally framed in terms of benefits for oneself rather than herd immunity. We wanted to make explicit one rationale - seeking immunity for oneself -that might sustain some young adults' decision to not follow public health recommendations. The wording of the question left open the possibility for respondents to think freely about the various nonhealth-related risks and benefits of willingly being infected in answering the question. We did not want to focus on the argument of herd immunity, as we believe it to be too sophisticated to naturally arise in individuals' decision making.

We found that psychological anxiety is a significant determinant of the WiRE, as are economic conditions and health risk beliefs. Additional regressions showed that psychological anxiety was higher for individuals with insecure employment and for those who thought they might have already been infected (SA Table C.4.). However, including this variable in the model did not change the estimated effects for economic conditions or health risk beliefs. This result suggests that governments' economic and social measures related to COVID should be complemented by specific actions related to mental health. This would also help increase compliance with physical distancing recommendations.

We interpret the positive effects of unemployment and income as evidence that economic anxiety - the fear of economic losses ${ }^{42}$ - partly relates to the opportunity costs of self-protection efforts on the WiRE. Unemployed respondents may prefer to be infected as soon as possible so as to be more productive later while searching for or starting a job. High-income respondents may anticipate high income losses if self-protection efforts somehow decrease their productivity. Importantly, the positive income effect cannot be explained by a lower risk aversion in high-income individuals or by a lower discount rate, as we controlled for monetary risk aversion and time preference. To specifically test for the moderating role of economic expectations, we estimated a model where income was interacted with a dummy variable taking a value of 1 if the respondent anticipated a possible decrease in income at a one-year time horizon and 0 otherwise (see SA A.5 for the definition of the variable). We found a significant positive effect of income for pessimistic respondents only (see SA Figure C.3).

We found a negative, albeit small, effect of risk beliefs on the WiRE. One policy issue, then, is whether communicating about health risks can be counterproductive. We analysed the impact of the daily death toll on respondents' risk perceptions, since we knew when they responded to the survey (the day and hour) and the daily death toll was announced each day at approximately 7:00 pm by the government. In April, over the survey period, the average death toll stood approximately at $800 \mathrm{We}$ found that a reduction in daily deaths by 100 was associated with a decrease in the perceived hospitalisation risk of -0.2-0.3 pp (SA Table C.4). Hence, more 
effectively informing young adults about the actual health risks (not just mortality but also morbidity) may help increase their self-protection efforts.

We also illustrate the critical role of family orientation, which was negatively related to the WiRE. Caring for others, especially one's relatives, is thus an important motivation for avoiding risk exposure. However, the effect of unemployment was also markedly higher in more familyoriented individuals. This suggests that the same 'social value' can have very heterogeneous effects, depending on the individual's specific situation. For family-oriented, unemployed individuals, a pressing need for resources to support one's family may actually increase risktaking behaviours.

This study is somewhat limited by the lack of socioeconomic representativity of our sample. Comparisons with statistics from the French National Statistics Office (INSEE) show that lowincome populations are overrepresented, with a poverty rate of approximately $34 \%$ for individuals 18-29 years old compared to the national rate of $19.7 \%$ in the INSEE data ${ }^{43}$, chap. 5.5. This reflects the relatively lower opportunity cost of time of subjects recruited by online survey companies. This bias in recruitment may be an advantage, as low-income populations are bearing disproportionate health and economic burdens from the epidemic. It would nonetheless be worth testing whether our conclusions hold true in a more representative sample.

As the second wave of infections has largely been driven by young adults, it is crucial to better understand the determinants of their (lack of) physical distancing efforts. Here, we analysed the possibility that some of these young adults are willing to risk being infected. Whether their actual behaviour is based upon such risk attitudes deserves further investigation.

This study has three important implications for public health communication strategies. First, the motives for self-protection or self-exposure are very heterogeneous, and different categories of young adults are likely to be sensitive to different messages. Second, emphasising that some social events carry high risks of infection might have the unintended consequence of making these events more desirable for some young adults. Third, public communication should avoid increasing perceived uncertainty about the health effects of the virus, or about the social and economic consequences of the outbreak, as this may foster anxiety and therefore increase risk exposure. 


\section{Tables and Figures}

Table 1. Sample characteristics of survey respondents.

\begin{tabular}{|c|c|c|c|c|}
\hline \multirow[b]{3}{*}{ Number of observations } & \multirow{3}{*}{$\begin{array}{c}\text { Full sample } \\
3,100\end{array}$} & \multicolumn{3}{|c|}{ "COVID negative } \\
\hline & & All & Women & Men \\
\hline & & $2,880(92.9 \%)$ & 1,471 & 1,409 \\
\hline \multicolumn{5}{|c|}{ Socio-demographic characteristics (\%) } \\
\hline Woman & 50.6 & 51.1 & 100.0 & 0.0 \\
\hline $18-25$ years old & 50.0 & 50.3 & 55.6 & 44.7 \\
\hline $26-35$ years old & 50.0 & 49.7 & 44.4 & 55.3 \\
\hline Born in France & 95.2 & 95.3 & 96.5 & 94.1 \\
\hline \multicolumn{5}{|c|}{ Schooling (\%) } \\
\hline Less than Baccalaureate & 15.2 & 15.1 & 10.7 & 19.7 \\
\hline Baccalaureate & 31.1 & 31.5 & 31.1 & 31.9 \\
\hline Higher education & 53.7 & 53.4 & 58.2 & 48.4 \\
\hline \multicolumn{5}{|c|}{ Household structure (\%) } \\
\hline Has a partner & 50.0 & 49.4 & 48.5 & 50.4 \\
\hline Has a child & 20.7 & 20.6 & 20.3 & 20.9 \\
\hline Couple with a child & 18.0 & 17.9 & 16.8 & 19.1 \\
\hline Single parent family & 2.6 & 2.6 & 3.5 & 1.8 \\
\hline Couple without children & 32.0 & 31.5 & 31.7 & 31.3 \\
\hline Single or separated & 47.3 & 47.9 & 48.0 & 47.8 \\
\hline \multicolumn{5}{|c|}{ Income per UC $(€ /$ month $)$} \\
\hline Mean & 1,660 & 1,653 & 1,554 & 1,756 \\
\hline Median & 1,400 & 1,400 & 1,333 & 1528 \\
\hline Q25 (25 th percentile) & 933 & 933 & 800 & 1000 \\
\hline Q75 (75 ${ }^{\text {th }}$ percentile $)$ & 3,333 & 3,333 & 1,945 & 2,333 \\
\hline Standard deviation & 1,165 & 1,160 & 1,093 & 1,218 \\
\hline \multicolumn{5}{|c|}{ Labour force status (\%) } \\
\hline Student & 30.3 & 30.6 & 33.5 & 27.5 \\
\hline Permanent job & 42.7 & 42.1 & 37.7 & 46.6 \\
\hline Temporary job & 12.0 & 12.2 & 13.9 & 10.5 \\
\hline Self-employed & 5.3 & 5.3 & 4.4 & 6.2 \\
\hline Unemployed & 5.6 & 5.8 & 6.5 & 5.0 \\
\hline Out of LF/Other & 4.0 & 4.1 & 4.1 & 4.0 \\
\hline \multicolumn{5}{|c|}{ Self-reported COVID status (\%) } \\
\hline COVID negative: sure & 66.3 & 71.4 & 70.3 & 72.5 \\
\hline COVID negative: unsure & 26.6 & 28.6 & 29.7 & 27.5 \\
\hline COVID positive & 7.1 & - & - & - \\
\hline \multicolumn{5}{|c|}{ Social values and family orientation } \\
\hline Trust (0-10 score) & 4.18 & 4.18 & 4.02 & 4.34 \\
\hline Reciprocity (Gift in $€$ ) & 19.19 & 19.15 & 18.66 & 19.67 \\
\hline Family orientation & 1.45 & 1.45 & 1.46 & 1.45 \\
\hline
\end{tabular}

Notes: except for income, trust, reciprocity and family orientation, the numbers are sample percentages. Family orientation is calculated by dividing closeness with relatives by closeness with non-relatives. 
Table 2. Effect heterogeneity by trust and family orientation

\begin{tabular}{|c|c|c|c|c|}
\hline & \multicolumn{2}{|c|}{ Trust } & \multicolumn{2}{|c|}{ Family orientation } \\
\hline & Low & High & Low & High \\
\hline \multirow[t]{2}{*}{ Household income/UC (z-score) } & $3.226 * * *$ & $2.294^{* *}$ & $3.097 * * *$ & $2.334 * *$ \\
\hline & $(1.131)$ & $(0.933)$ & $(0.957)$ & $(0.910)$ \\
\hline \multirow[t]{2}{*}{ Unemployed } & $12.357 * * *$ & 4.936 & 6.155 & $8.977 * *$ \\
\hline & $(4.595)$ & $(4.299)$ & $(4.032)$ & $(3.531)$ \\
\hline $\mathrm{N}$ observations & 2,859 & 2,859 & 2,859 & 2,859 \\
\hline
\end{tabular}


Figure 1: Distribution of willingness to risk exposure by COVID negative status

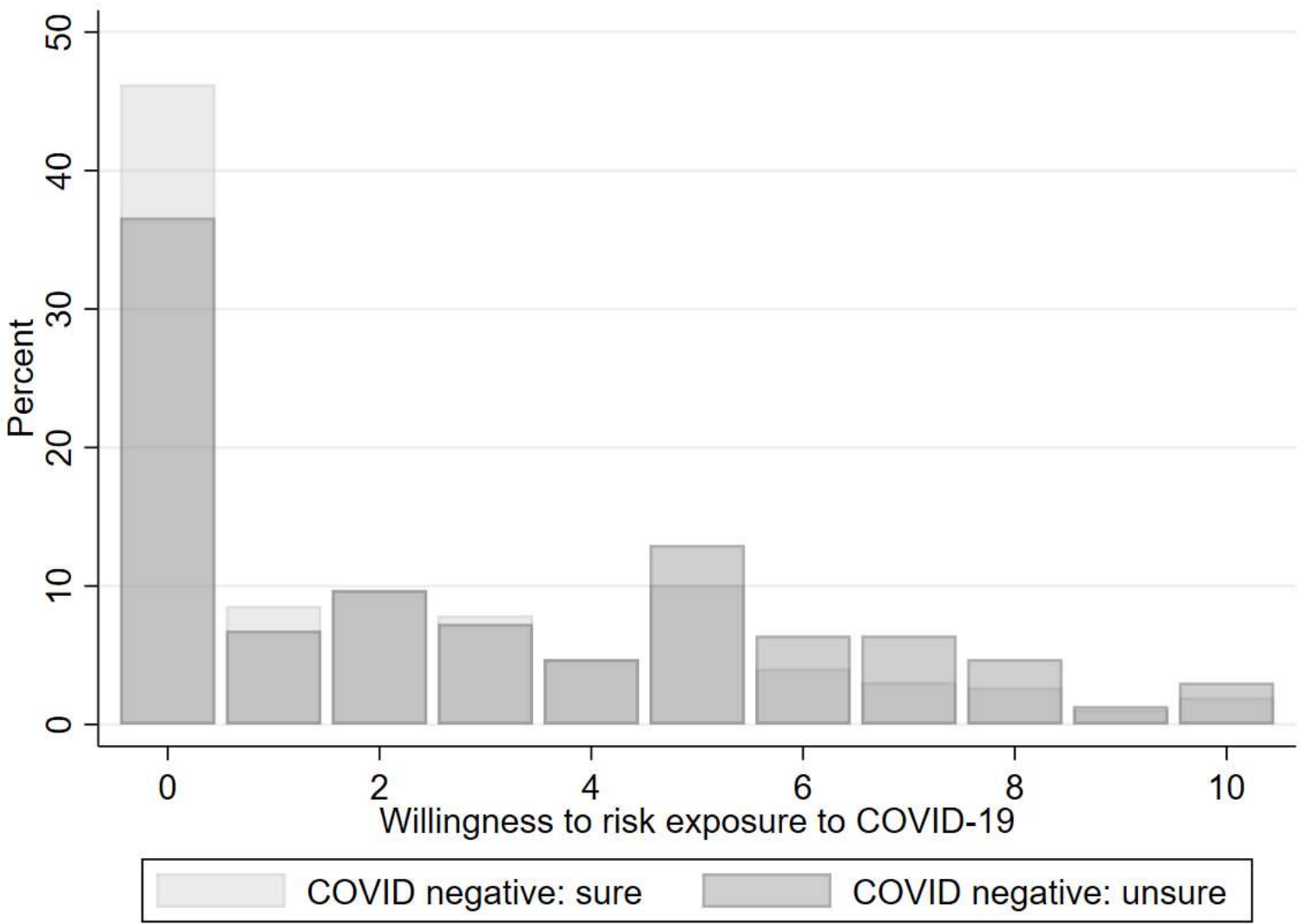

Figure 2: Beliefs about COVID-19

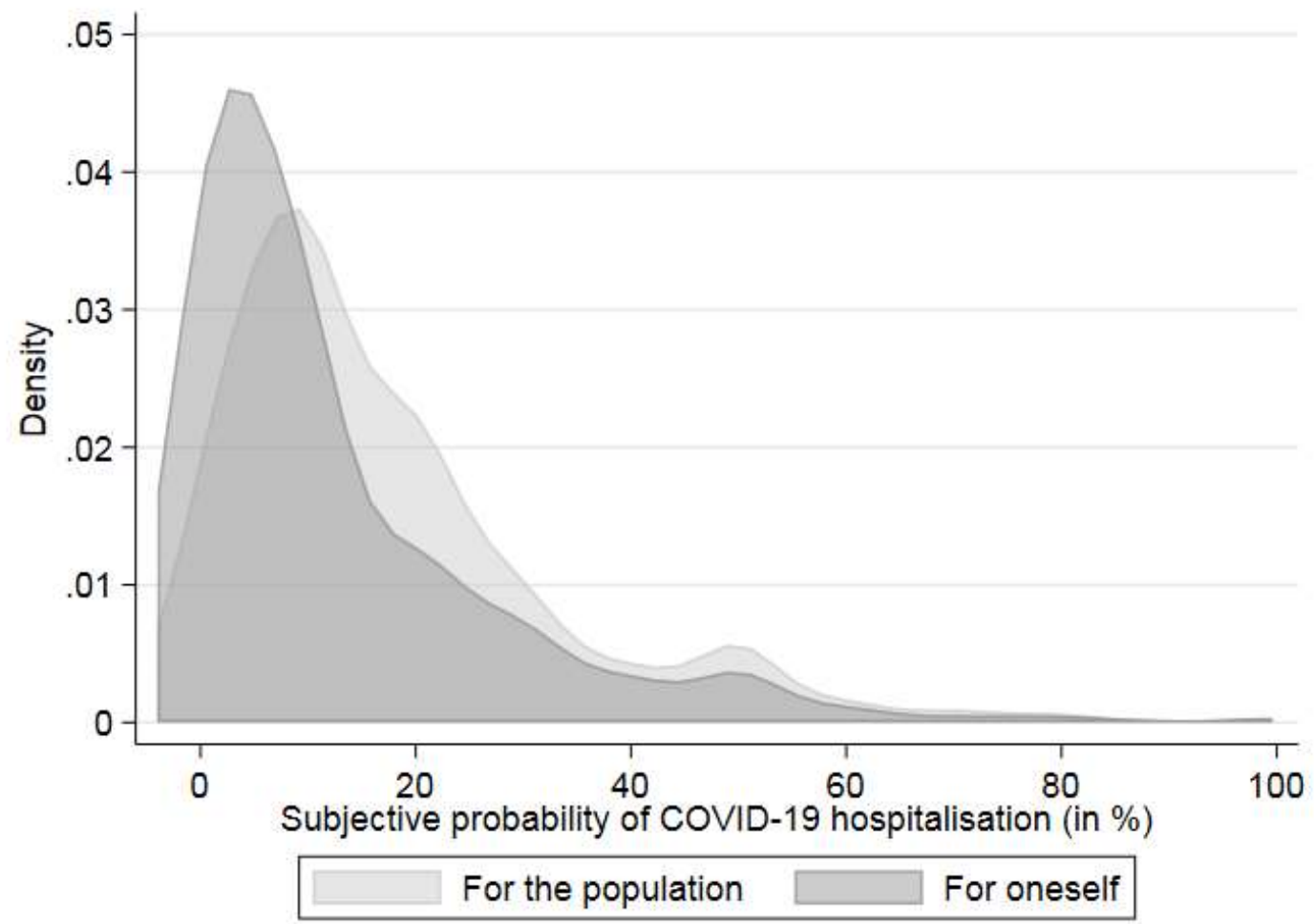


Figure 3 - Distribution of status anxiety scores
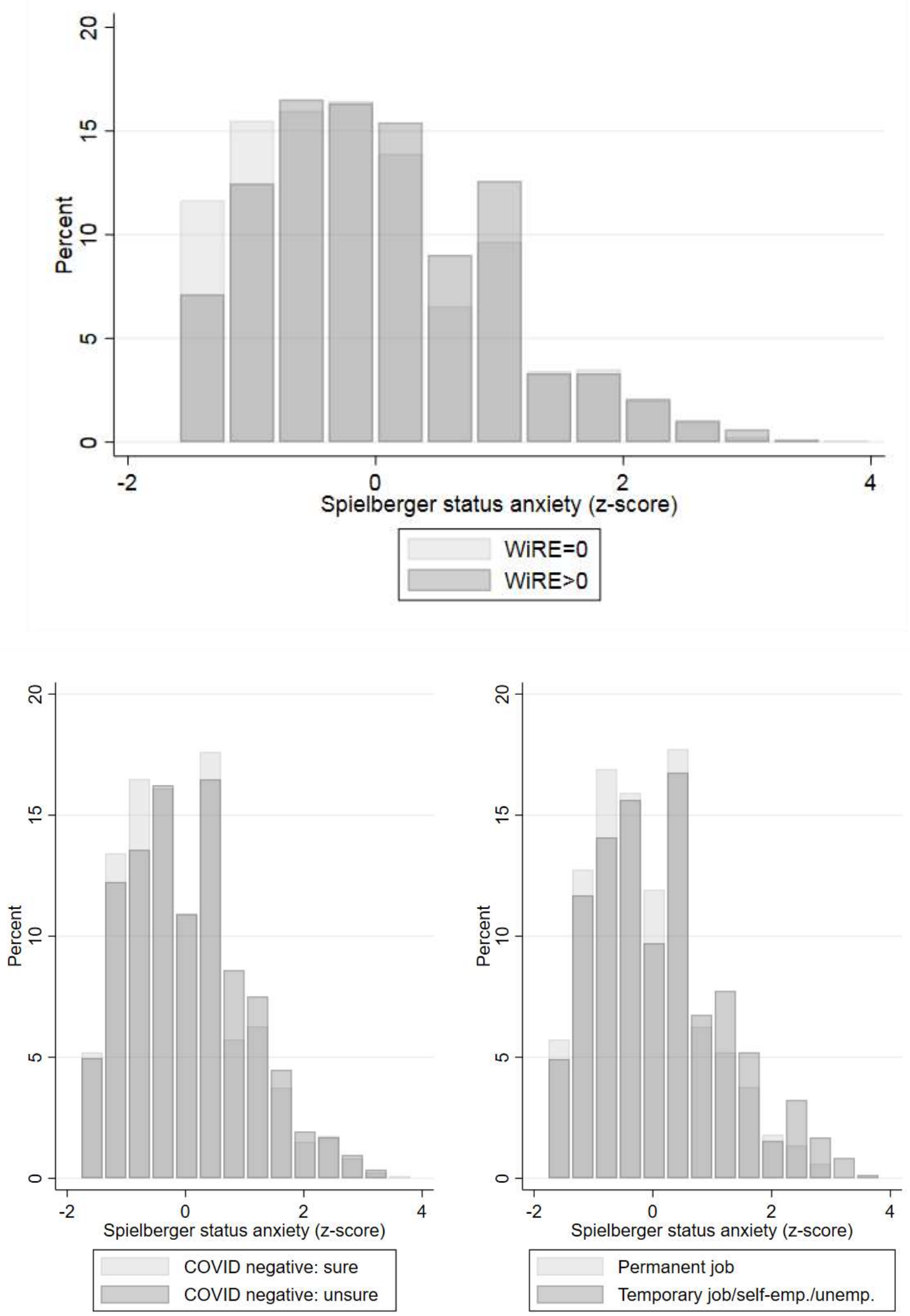


\section{Figure 4. Impact of economic conditions, COVID risk beliefs and anxiety}

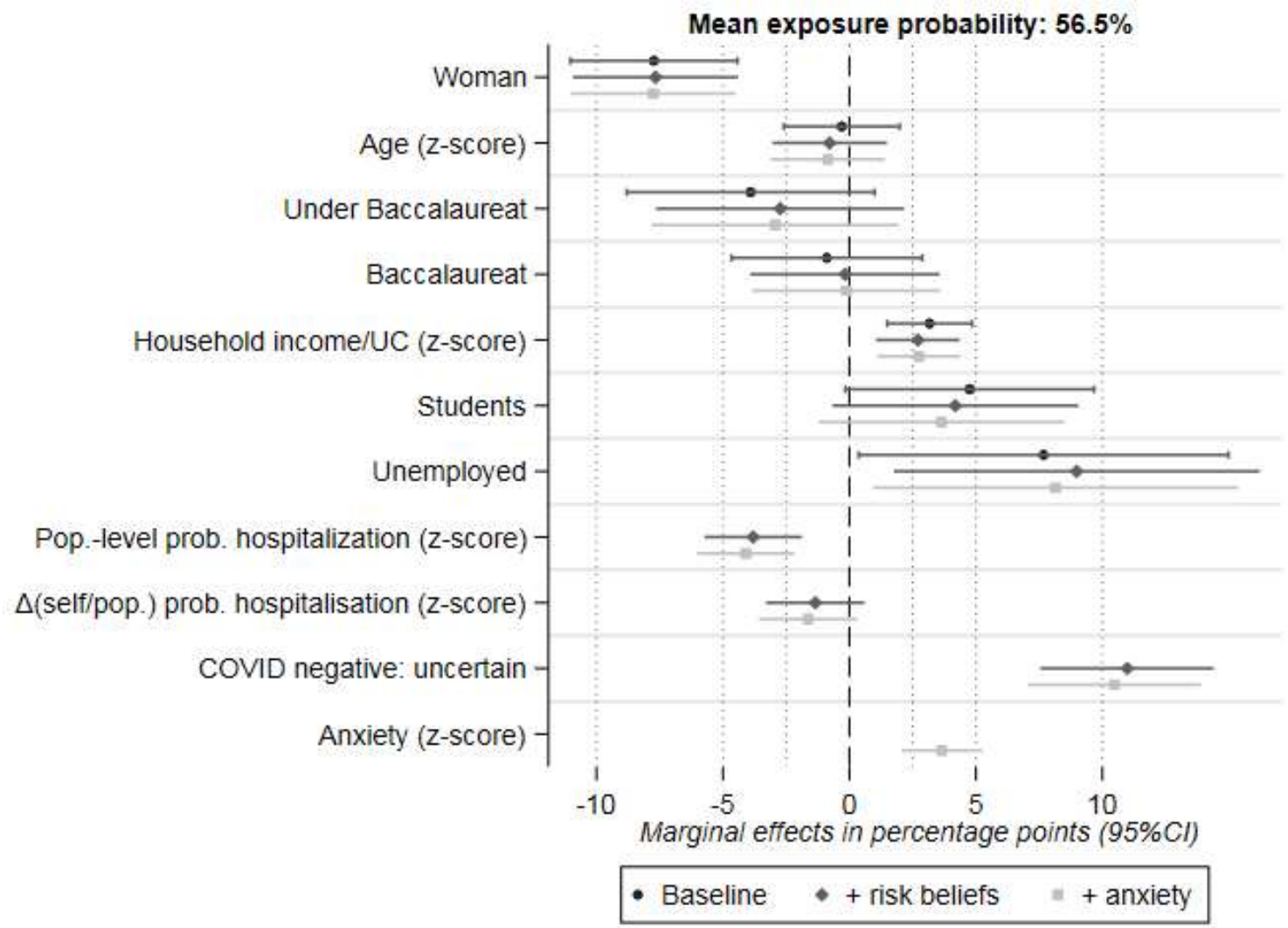

Notes: Full results presented in Appendix C, Table C1. Baseline results correspond to Appendix C, Table C1, Specification 2. The results with the addition of health risk beliefs correspond to Appendix C, Table C1, Specification 3. The results with the addition of health risk beliefs and anxiety correspond to Appendix C, Table C1, Specification 4. 


\section{Bibliography}

1 Fontanet, A. \& Cauchemez, S. COVID-19 herd immunity: where are we? Nature Reviews Immunology 20, 583-584, doi:10.1038/s41577-020-00451-5 (2020).

2 Alvarez, F. E., Argente, D. \& Lippi, F. A simple planning problem for covid-19 lockdown. National Bureau of Economic Research Working Paper (Preprint) 26981, doi:10.3386/w26981 (2020).

3 Giordano, G. et al. Modelling the COVID-19 epidemic and implementation of population-wide interventions in Italy. Nature medicine 26, 855-860 (2020).

4 Kucharski, A. J. et al. Effectiveness of isolation, testing, contact tracing and physical distancing on reducing transmission of SARS-CoV-2 in different settings. medRxiv, 2020.2004.2023.20077024, doi:10.1101/2020.04.23.20077024 (2020).

5 Fenichel, E. P. et al. Adaptive human behavior in epidemiological models. Proceedings of the National Academy of Sciences 108, 6306-6311 (2011).

6 Toxvaerd, F. Equilibrium social distancing. Cambridge-INET Working Paper Series (Preprint) 08 (2020).

7 Geoffard, P.-Y. \& Philipson, T. Rational Epidemics and Their Public Control. International Economic Review 37, 603-624 (1996).

8 Reluga, T. C. \& Li, J. Games of age-dependent prevention of chronic infections by social distancing. Journal of mathematical biology 66, 1527-1553 (2013).

9 Van Bavel, J. J. et al. Using social and behavioural science to support COVID-19 pandemic response. Nature Human Behaviour, 1-12 (2020).

10 Anderson, E., Carleton, N., Diefenbach, M. \& Han, P. The relationship between uncertainty and affect. Frontiers in Psychology 10, 2504 (2019).

11 Hirsh, J. B., Mar, R. A. \& Peterson, J. B. Psychological entropy: A framework for understanding uncertainty-related anxiety. Psychological Review 119, 304-320, doi:https://doi.org/10.1037/a0026767 (2012).

$12 \mathrm{Wu}, \mathrm{G}$. Anxiety and decision making with delayed resolution of uncertainty. Theory and Decision 46, 159-199 (1999).

13 Kreps, D. M. \& Porteus, E. L. Temporal resolution of uncertainty and dynamic choice theory. Econometrica 46, 185-200 (1978).

14 Strzalecki, T. Temporal resolution of uncertainty and recursive models of ambiguity aversion. Econometrica 81, 1039-1074 (2013).

15 Falk, A. \& Zimmermann, F. Beliefs and utility: Experimental evidence on preferences for information. CESifo Working Paper (Preprint) 6061, 1-70 (2016).

16 Ganguly, A. \& Tasoff, J. Fantasy and dread: The demand for information and the consumption utility of the future. Management Science 63, 4037-4060 (2017).

17 Freeston, M. H., Rhéaume, J., Letarte, H., Dugas, M. J. \& Ladouceur, R. Why do people worry? Personality and individual differences 17, 791-802 (1994).

18 Brotherhood, L., Kircher, P., Santos, C. \& Tertilt, M. An Economic Model of the Covid19 Epidemic: The Importance of Testing and Age-Specific Policies. CESifo Working Paper (Preprint) 8316 (2020).

19 Finucane, M. L. in Handbook of Risk Theory: Epistemology, Decision Theory, Ethics, and Social Implications of Risk (eds Sabine Roeser, Rafaela Hillerbrand, Per Sandin, \& Martin Peterson) 677-691 (Springer Netherlands, 2012).

20 Loewenstein, G. Emotions in economic theory and economic behavior. American economic review 90, 426-432 (2000).

21 Quaas, M. F. et al. The Social Cost of Contacts: Theory and Evidence for the COVID19 Pandemic in Germany. CESifo Working Paper (Preprint) 8347 (2020). 
22 Alfaro, L., Faia, E., Lamersdorf, N. \& Saidi, F. Social Interactions in Pandemics: Fear, Altruism, and Reciprocity. 27134, doi:10.3386/w27134 (2020).

23 Campos-Mercade, P., Meier, A., Schneider, F. \& Wengström, E. Prosociality predicts health behaviors during the COVID-19 pandemic. University of Zurich, Department of Economics, Working Paper (Preprint) (2020).

24 Bartscher, A. K., Seitz, S., Slotwinski, M., Siegloch, S. \& Wehrhöfer, N. Social capital and the spread of Covid-19: Insights from European countries. CESifo Working Papers 8346, 1-57 (2020).

25 Borgonovi, F. \& Andrieu, E. Bowling together by bowling alone: Social capital and Covid-19. Covid Economics 17, 73-96 (2020).

26 Brodeur, A., Grigoryeva, I. \& Kattan, L. Stay-At-Home Orders, Social Distancing and Trust. IZA Discussion Paper (Preprint) 13234 (2020).

27 Durante, R., Guiso, L. \& Gulino, G. Asocial capital: Civic culture and social distancing during COVID-19. Universitat Pompeu Fabra Economic Working Papers (Preprint) 1723, 1-31 (2020).

28 Sheth, K. \& Wright, G. The Usual Suspects: Does Risk Tolerance, Altruism, and Health Predict the Response to COVID-19? CESifo Working Paper (Preprint) 8276 (2020).

29 Berg, J., Dickhaut, J. \& McCabe, K. Trust, reciprocity, and social history. Games and economic behavior 10, 122-142 (1995).

30 Welch, M. R. et al. Determinants and consequences of social trust. Sociological Inquiry 75, 453-473 (2005).

31 Nannestad, P. What have we learned about generalized trust, if anything? Annual Review of Political Science 11, 413-436 (2008).

32 Coleman, J. S. The Foundation of Social Theory. (Harvard University Press, 1991).

33 Abbott, S. \& Freeth, D. Social capital and health: starting to make sense of the role of generalized trust and reciprocity. Journal of Health Psychology 13, 874-883 (2008).

34 Ehsan, A., Klaas, H. S., Bastianen, A. \& Spini, D. Social capital and health: A systematic review of systematic reviews. SSM-population health 8, 100425 (2019).

35 Moore, S. \& Kawachi, I. Twenty years of social capital and health research: a glossary. Journal of Epidemiology and Community Health 71, 513-517 (2017).

36 HAS. Cahier des charges définissant les modalités d'évaluation des performances des tests sérologiques détectant les anticorps dirigés contre le SARS-CoV-2. Vol. 16 Avril (Haute Autorité de Santé, 2020).

37 Gauthier, J. \& Bouchard, S. Adaptation canadienne-française de la forme révisée du State-Trait Anxiety Inventory de Spielberger. Canadian Journal of Behavioural Science/Revue canadienne des sciences du comportement 25, 559-578 (1993).

38 Caroli, E. \& Weber-Baghdiguian, L. Self-reported health and gender: The role of social norms. Social Science \& Medicine 153, 220-229 (2016).

39 Reeskens, T. \& Hooghe, M. Cross-cultural measurement equivalence of generalized trust. Evidence from the European Social Survey (2002 and 2004). Social Indicators Research 85, 515-532 (2008).

40 Falk, A. et al. Global evidence on economic preferences. The Quarterly Journal of Economics 133, 1645-1692 (2018).

41 Aron, A., Aron, E. N. \& Smollan, D. Inclusion of other in the self scale and the structure of interpersonal closeness. Journal of Personality and Social psychology 63, 596-612 (1992).

42 Fetzer, T., Hensel, L., Hermle, J. \& Roth, C. Coronavirus perceptions and economic anxiety. Review of Economics and Statistics, 1-36 (2020).

43 INSEE. Tableaux de l'économie française. (Institut National de la Statistique et des Etudes Economiques, 2020). 


\section{Acknowledgements}

The authors are grateful to all participants for providing the data used in this study. The present study was supported by a research grant from AXA Research (AXA Award 2015 - FE). We also acknowledge administrative support from the Paris School Economics via the Agence Nationale de la Recherche EUR grant ANR-17-EURE-0001. The funders had no role in the design or conduct of the study; the collection, management, analysis, or interpretation of the data; or the preparation, review, or approval of this manuscript.

\section{Authors' contributions}

FE conceived of the study and contributed to all steps. PYG contributed to the design of the empirical analysis and participated in the literature search and the development of the manuscript. Both authors read and approved the manuscript. The corresponding author attests that both listed authors meet the authorship criteria and that no others meeting the criteria have been omitted. FE is the study guarantor.

\section{Competing interests}

The authors have no competing interests to declare.

\section{Additional information}

A Supplementary Appendix for this paper is available at https://osf.io/gesyt/. It includes information on the study design and methods, the full results tables, and supplementary analyses.

The research design, questions, and outcomes were developed without the participants' involvement. Participants were not asked to contribute to the interpretation or writing of the results. Participant anonymity and RGPD compliance were guaranteed by Qualtrics. The study was approved by the Paris School of Economics IRB (Certificate 2020-009). Although PYG is a member of the Paris School of Economics IRB, PYG did not participate in reviewing the proposal.

This study is based on data from an online survey that was comprised of an experiment followed by a questionnaire. The current study only used the data from the questionnaire. The experiment was unrelated to the COVID-19 outbreak, as shown by the pre-registration in the Open Science Framework (https://osf.io/mhty3). Data and replication codes are available at https://osf.io/gesyt/. 